\title{
Clinical factors associated with early readmission among acutely decompensated heart failure patients
}

Bredy Pierre-Louis ${ }^{1}$, Shareen Rodriques², Vanessa Gorospe ${ }^{3}$, Achuta K. Guddati ${ }^{4}$, Wilbert S. Aronow ${ }^{5}$, Chul Ahn ${ }^{6}$, Maurice Wright ${ }^{1}$

\author{
${ }^{1}$ Columbia University Medical Center, Harlem Hospital Center, New York, NY, USA \\ ${ }^{2}$ St. Mary's Medical Center, Huntington, West Virginia, USA \\ ${ }^{3}$ Hartford Hospital, Harford, CT, USA \\ ${ }^{4}$ SUNY Downstate Medical Center, Brooklyn, NY, USA \\ ${ }^{5}$ Westchester Medical Center/New York Medical College, Valhalla, NY, USA \\ ${ }^{6}$ Southwestern Medical Center, University of Texas, Dallas, TX, USA
}

Submitted: 21 January 2015

Accepted: 1 February 2015

Arch Med Sci 2016; 12, 3: 538-545

DOI: 10.5114/aoms.2016.59927

Copyright $\odot 2016$ Termedia \& Banach

\section{Abstract}

Introduction: Congestive heart failure (CHF) is a common cause of hospital readmission.

Material and methods: A retrospective study was conducted at Harlem Hospital in New York City. Data were collected for 685 consecutive adult patients admitted for decompensated CHF from March, 2009 to December, 2012. Variables including patient demographics, comorbidities, laboratory studies, and medical therapy were compared between CHF patient admissions resulting in early $\mathrm{CHF}$ readmission and not resulting in early $\mathrm{CHF}$ readmission.

Results: Clinical factors found to be independently significant for early CHF readmission included chronic obstructive pulmonary disease (odds ratio $(O R)=6.4)$, HIV infection ( $O R=3.4)$, African-American ethnicity $(O R=2.2)$, systolic heart failure $(O R=1.9)$, atrial fibrillation $(O R=2.3)$, renal disease with glomerular filtration rate $<30 \mathrm{ml} / \mathrm{min}(O R=2.7)$, evidence of substance abuse $(O R=1.7)$, and absence of angiotensin-converting enzyme inhibitors or angiotensin receptor blocker therapy after discharge $(O R=1.8)$. The ORs were used to develop a scoring system regarding the risk for early readmission.

Conclusions: Identifying patients with clinical factors associated with early $\mathrm{CHF}$ readmission after an index hospitalization for CHF using the proposed scoring system would allow for an early CHF readmission risk stratification protocol to target particularly high-risk patients.

Key words: congestive heart failure, risk factors, heart failure readmission.

\section{Introduction}

Despite significant advances in diagnostic evaluations and therapeutic interventions, congestive heart failure (CHF) remains a major and growing clinical reality characterized by high morbidity, mortality and economic burden [1]. Congestive heart failure affects $2 \%$ of the United States population, with an estimated 5.1 million Americans aged 20 years and older affected, and by 2030 the prevalence of CHF will increase by $25 \%$ [2]. The incidence of CHF is approximately 10 per 1000 among people over

\author{
Corresponding author: \\ Wilbert S. Aronow MD, \\ FACC, FAHA \\ Cardiology Division \\ New York Medical College \\ Macy Pavilion \\ Room 138 \\ Valhalla, NY 10595 \\ Phone: (914) 493-5311 \\ Fax: (914) 235-6274 \\ E-mail:wsaronow@aol.com
}


65 years of age, with African Americans having the highest risk of developing CHF, followed by Latinos, whites, and Asian Americans (4.6, 3.5, 2.4 and 1.0 per 1000 person years, respectively) [3]. Early hospital readmission for $\mathrm{CHF}$ is a major health care and economic problem in the United States, especially in African Americans and Latinos.

Congestive heart failure is a progressive medical problem with concomitant high mortality. One in 9 deaths in the United States involve heart failure [2]. Congestive heart failure accounts for approximately 277,000 deaths annually in the United States and approximately $34 \%$ of cardiovascular-related deaths. Approximately $50 \%$ of persons diagnosed with CHF will die within 5 years [2]. Mortality is closely associated with decompensated CHF requiring hospital admission, particularly frequent admissions and early (60 days or less) readmissions [4]. Despite advances in the management of $\mathrm{CHF}$ and multiple studies investigating the predictors of early $\mathrm{CHF}$ readmission, the rates remain unacceptably high. Congestive heart failure remains the leading cause of hospital admission for patients over 65 years of age, and readmissions have implications for patients, hospitals and third-party payers. Congestive heart failure readmission portends a poor prognosis for the patient, with a median survival of 18 to 24 months after hospital discharge [5]. Three percent of African Americans are affected by $\mathrm{CHF}$ compared to $2 \%$ of the general population [6]. Notably, African Americans have a disproportionately high incidence of hypertension (32\%) as an etiology of left ventricular dysfunction when compared to white patients $(4 \%)[7,8]$.

A retrospective analysis of the military health system's TRICARE program revealed that a significant proportion of African Americans and Latinos received less evidence-based $\mathrm{CHF}$-related care in terms of $\beta$-blocker and angiotensin-converting enzyme inhibitor (ACEI)/angiotensin receptor blocker (ARB) therapy compared to whites $(53.4 \%$ and $49.2 \%$ vs. $58.3 \% ; p<0.0001$ ) [9]. Interestingly, this study found no significant differences in the odds of rehospitalization in the same groups. An analysis of Medicare patients from 2006 to 2008 showed that Latino patients had a higher rate of CHF readmission compared to whites $(27.9 \%$ vs. $25.9 \%, p<0.001$ ) [10]. This study found a similar trend in African Americans, where the CHF readmission rate was higher compared to whites (27.9\% vs. $27.1 \%, p<0.01)$ [11]. Congestive heart failure also results in a significant financial burden, with 2030 total cost projections estimated to increase by almost $120 \%$ to $\$ 70$ billion from current expenditures of $\$ 32$ billion annually [2]. Hospitalizations account for an estimated $75 \%$ of the direct costs associated with heart failure.
Early CHF readmissions are often related to clinical and patient concerns (comorbidity management, medical non-compliance, lack of early outpatient follow-up care, lack of support structures at home) which are not resolved during the index hospitalization. Disease progression with worsening severity also contributes to early readmissions [12]. Therefore, early readmissions are increasingly being viewed as avoidable and an indicator of poor care or an inadequately coordinated health system [13]. For these reasons, in addition to the significant associated costs, the Centers for Medicare and Medicaid Services (CMS) began public reporting of hospital early readmission rates for $\mathrm{CHF}$ and also implemented penalties for hospitals with high and excessive early readmission rates [14]. Resource-limited hospitals serving low-income populations and communities, which often have high early readmission rates for $\mathrm{CHF}$, will be most affected by these measures. The reduction in reimbursement to hospitals and healthcare systems already struggling with the challenges of providing quality care to underserved and vulnerable patient populations will likely exacerbate the very concerns CMS hopes to address. Therefore, these hospital and healthcare systems must implement protocols to identify CHF patients at high risk for readmission and allocate resources to reduce their $\mathrm{CHF}$ early readmission rates.

There is a paucity of studies evaluating the relative importance of the previously identified predictors of early readmission specifically for a predominantly African-American and Latino, underserved, urban, and low-income population [15]. Additionally, there are likely precipitants of decompensated $\mathrm{CHF}$ that are unique and represent more of a burden in this patient population because of socioeconomic factors [3]. The few prior studies that were conducted in these populations involved only small numbers of patients followed over a short study period. Therefore, the aim of this study is to identify the clinical factors and predictors of early (< 60 day) readmission for CHF specifically for a predominantly African-American and Latino underserved urban population. Determination of the relative contribution of these factors and predictors will enable identification of high-risk patients who would benefit from a more intensified, goal-directed, customized, multidisciplinary management program initiated during their index admission and continued after discharge. These interventions will ideally be effective in reducing CHF readmissions, improving patients' morbidity and mortality, and reducing health care costs while preserving hospital reimbursements.

\section{Material and methods}

A retrospective study was conducted at Harlem Hospital Center in New York City after obtaining 
Institutional Review Board approval for the research protocol. Data were collected for 685 consecutive adult patients ( $\geq 18$ years old) admitted for decompensated CHF (systolic and diastolic heart failure) from January, 2009 to December, 2012 to determine the clinical factors associated with early CHF readmission. Systolic CHF was defined as an echocardiographic left ventricular ejection fraction of $<40 \%$ in a patient presenting with signs and symptoms of CHF [15]. Diastolic heart failure was defined as a preserved, normal left ventricular ejection fraction with diastolic dysfunction by echocardiography in a patient presenting with signs and symptoms of CHF. Patients with diastolic CHF were identified based on previously established guidelines [16-18]. Variables, including patient demographics, comorbidities (including substance abuse supported by patient history and blood and urine toxicology studies, primarily alcohol and cocaine), laboratory studies, and medical therapy prescribed at the time of discharge were compared between CHF patient admissions resulting in an early readmission for $\mathrm{CHF}$, defined as within 60 days, and those not resulting in early readmission.

Patients were all adults ( $\geq 18$ years old) admitted and discharged with a primary diagnosis of decompensated CHF from the internal medical inpatient service. Patients were excluded if they were known to have stable CHF but admitted for an unrelated medical problem with no clinical evidence of $\mathrm{CHF}$ decompensation. The diagnosis of CHF was made clinically based on symptoms and signs of pulmonary and systemic venous congestion and/ or manifestations of tissue hypoperfusion [19]. Echocardiographic findings, including left ventricular ejection fraction and evidence of diastolic dysfunction, and biomarkers such as brain natriuretic peptide (BNP) were also incorporated into the diagnostic evaluation. The majority of the patients were admitted through the Emergency Department, but some were transferred from other services (primarily medicine or subspecialty clinics).

\section{Statistical analysis}

The baseline characteristics were compared between early admission and no early admission groups using the two-sample $t$-test or the Wilcoxon rank-sum test for continuous variables and $\chi^{2}$ tests for categorical variables. $\chi^{2}$ tests were used to investigate the association between early readmission and clinical factors. Univariate logistic regression was used to estimate the probability of early readmission (PER) associated with each of these clinical factors. Baseline characteristics and clinical factors with $p$-values $<0.20$ were entered as candidate variables for stepwise multiple logistic regression. Stepwise logistic regression analysis was conducted to identify significant independent factors associated with early admission. The odds ratios obtained from stepwise logistic regression were used to assign the scores to the independent clinical factors associated with early readmission points. A weighted scoring system was created by rounding all regression coefficients in the final model to the nearest integer.

\section{Results}

Six hundred eighty-five consecutive hospital patient admissions for decompensated CHF were evaluated in the study. One hundred thirty-six early readmissions for decompensated CHF were identified, resulting in an early readmission rate of $19.85 \%$. The baseline characteristics for patients who experienced an early CHF readmission, for those who did not experience an early CHF readmission, and $p$ values for comparison are presented in Table I. There were no significant differences in medical therapy prescribed at hospital discharge. The use of combined isosorbide dinitrate plus hydralazine (BiDil) therapy among a predominantly African-American patient population in this study was based on the A-Heft trial [20].

Table II shows the clinical parameters associated with early readmission with calculated odds ratios, 95\% confidence intervals, and $p$-values. Table III shows the significant independent baseline characteristics and clinical factors associated with early readmission using stepwise logistic regression analysis with a proposed scoring system for early CHF readmission. The odds ratio integer was used to assign each clinical factor a point.

The assigned points of the independently significant clinical factors for early CHF readmission were formulated into a risk score to assess the relative probability of early readmission based on a cumulative scoring system, which is summarized in Table IV. While this scoring system needs further validation in prospective studies, it establishes the possibility of developing a risk stratification model among the studied patient population regarding early $\mathrm{CHF}$ readmission.

\section{Discussion}

The clinical factors in this study independently associated with early $\mathrm{CHF}$ readmission after an index hospitalization for CHF among a predominantly African-American and Latino underserved urban population have a specific impact on the pathophysiology and therapeutic management of heart failure. They reflect a unique cohort of clinical predictors for early CHF readmission that affect a specific patient population which is at particularly high risk for adverse outcomes related to CHF. In addition, African Americans and Latinos 
Table I. Baseline characteristics of heart failure study patients

\begin{tabular}{|c|c|c|c|}
\hline Characteristics & Early re-admission & No early re-admission & $P$-value \\
\hline Patients & 136 & 549 & \\
\hline Age [years] & $63.7 \pm 15.2$ & $63.6 \pm 15.1$ & 0.973 \\
\hline Length of stay [days] & $5.9 \pm 5.6$ & $8.0 \pm 15.6$ & 0.009 \\
\hline Admission BNP [pg/ml] & $1636.1 \pm 1220.8$ & $1298.6 \pm 1272.0$ & $<0.0001$ \\
\hline Gender: & & & 0.7773 \\
\hline Female & $66(48.5 \%)$ & $259(47.2 \%)$ & \\
\hline Male & $70(51.5 \%)$ & $290(52.8 \%)$ & \\
\hline Ethnicity: & & & 0.0087 \\
\hline African-American & $125(91.9 \%)$ & $437(79.6 \%)$ & \\
\hline Latino & $9(6.6 \%)$ & $78(14.2 \%)$ & \\
\hline Other & $2(1.5 \%)$ & $34(6.1 \%)$ & \\
\hline Body mass index $>30 \mathrm{~kg} / \mathrm{m}^{2}$ & $41(30.1 \%)$ & $236(43.5 \%)$ & 0.0045 \\
\hline Hypertension & $126(92.6 \%)$ & $498(90.7 \%)$ & 0.4778 \\
\hline Diabetes mellitus & $43(31.6 \%)$ & $231(42.1 \%)$ & 0.0258 \\
\hline Dyslipidemia & $37(27.2 \%)$ & $134(24.4 \%)$ & 0.4997 \\
\hline Chronic obstructive pulmonary disease & $43(31.6 \%)$ & $55(10.0 \%)$ & $<0.0001$ \\
\hline Coronary artery disease & $36(26.5 \%)$ & $137(25.0 \%)$ & 0.7156 \\
\hline Atrial fibrillation & $41(30.1 \%)$ & $96(17.5 \%)$ & 0.001 \\
\hline Human immunodeficiency virus disease & $18(13.2 \%)$ & $25(4.6 \%)$ & 0.0002 \\
\hline Renal disease GFR $<60 \mathrm{ml} / \mathrm{min}$ & $53(39.0 \%)$ & $215(39.2 \%)$ & 0.9673 \\
\hline Renal disease GFR 30-59 ml/min & $33(24.3 \%)$ & $176(32.1 \%)$ & 0.0772 \\
\hline Renal disease GFR $<30 \mathrm{ml} / \mathrm{min}$ & $54(39.7 \%)$ & $158(28.8 \%)$ & 0.0136 \\
\hline Active smoker & $75(55.1 \%)$ & $233(43.7 \%)$ & 0.017 \\
\hline History of substance abuse & $57(41.9 \%)$ & $144(27.0 \%)$ & 0.0007 \\
\hline Aspirin & $108(79.4 \%)$ & $416(75.8 \%)$ & 0.3704 \\
\hline Statin & $96(70.6 \%)$ & $338(61.7 \%)$ & 0.0535 \\
\hline$\beta$-Blocker & $78(57.4 \%)$ & $317(58.0 \%)$ & 0.8992 \\
\hline ACEI/ARB & $91(66.9 \%)$ & $324(59.0 \%)$ & 0.0916 \\
\hline Digoxin & $24(18 \%)$ & $73(13 \%)$ & 0.198 \\
\hline Diuretics & $114(84 \%)$ & 451 (82\%) & 0.646 \\
\hline $\begin{array}{l}\text { BiDil (isosorbide dinitrate plus } \\
\text { hydralazine) }\end{array}$ & $39(28.7 \%)$ & $116(21.2 \%)$ & 0.061 \\
\hline Spironolactone & $6(4.4 \%)$ & $29(5.3 \%)$ & 0.671 \\
\hline
\end{tabular}

$B N P$ - brain natriuretic peptide, GFR - glomerular filtration rate, ACEI - angiotensin-converting enzyme inhibitor, ARB - angiotensin receptor blocker.

are at disproportionately high risk regarding the comorbidities identified in this study as predictors for early CHF readmission.

Chronic obstructive pulmonary disease (COPD) exacerbates the progression of $\mathrm{CHF}$ through mechanisms related to accelerated pulmonary hypertension and right-sided heart failure, which further compromises cardiac output [21]. In addition, patients with COPD have limited pulmonary reserve and likely experience $\mathrm{CHF}$ de- 
Table II. Clinical parameters associated with early readmission

\begin{tabular}{|c|c|c|c|c|c|}
\hline Clinical factor & $\begin{array}{c}\text { Early } \\
\text { readmission }\end{array}$ & $\begin{array}{l}\text { No early } \\
\text { readmission }\end{array}$ & $\begin{array}{c}\text { Odds ratio, } \\
(95 \% \mathrm{Cl})\end{array}$ & $P$-value & $\begin{array}{l}\text { Probability } \\
\text { of early } \\
\text { readmission } \\
\text { (PER) (\%) }\end{array}$ \\
\hline Smoker & $75 / 136(55 \%)$ & $233 / 533(44 \%)$ & $1.6(1.1-2.3)$ & 0.0170 & 24.4 \\
\hline African-American & $125 / 136(92 \%)$ & $437 / 549(80 \%)$ & $2.9(1.5-5.6)$ & 0.0008 & 22.2 \\
\hline Systolic heart failure & $92 / 132(70 \%)$ & $289 / 510(57 \%)$ & $1.8(1.2-2.7)$ & 0.0066 & 24.1 \\
\hline COPD & $43 / 136(32 \%)$ & $55 / 549(10 \%)$ & $4.2(2.6-6.6)$ & $<0.0001$ & 43.9 \\
\hline Atrial fibrillation & $41 / 136(30 \%)$ & $96 / 549(17 \%)$ & $2.0(1.3-3.1)$ & 0.0010 & 29.9 \\
\hline HIV disease & $18 / 136(13 \%)$ & $25 / 549(5 \%)$ & $3.2(1.7-6.1)$ & 0.0002 & 41.9 \\
\hline Renal disease GFR $<30 \mathrm{ml} / \mathrm{min}$ & $54 / 136(40 \%)$ & $158 / 549(29 \%)$ & $1.6(1.1-2.4)$ & 0.0136 & 25.5 \\
\hline History of substance abuse & $57 / 136(42 \%)$ & $144 / 534(27 \%)$ & $2.0(1.3-2.9)$ & 0.0007 & 28.4 \\
\hline $\operatorname{BNP}(\geq 1200 \mathrm{pg} / \mathrm{ml})$ & $73 / 136(54 \%)$ & $213 / 544(39 \%)$ & $1.8(1.2-2.6)$ & 0.0022 & 25.5 \\
\hline $\begin{array}{l}\text { Length of hospital stay } \\
\text { ( } \geq 25 \text { days) }\end{array}$ & $2 / 136(1 \%)$ & $34 / 544(6 \%)$ & $0.2(0.1-0.9)$ & 0.0297 & 5.6 \\
\hline
\end{tabular}

COPD - chronic obstructive pulmonary disease, HIV - human immunodeficiency virus, GFR - glomerular filtration rate, BNP - brain natriuretic peptide.

Table III. Proposed scoring system for early readmission

\begin{tabular}{|lcc|}
\hline Clinical factor & $\begin{array}{c}\text { Odds } \\
\text { ratio }\end{array}$ & $\begin{array}{c}\text { Assigned } \\
\text { points }\end{array}$ \\
\hline African-American & 2.2 & 2 \\
\hline $\begin{array}{l}\text { Chronic obstructive pulmonary } \\
\text { disease }\end{array}$ & 6.4 & 6 \\
\hline Atrial fibrillation & 2.3 & 2 \\
\hline $\begin{array}{l}\text { Human immunodeficiency } \\
\text { virus disease }\end{array}$ & 3.4 & 3 \\
\hline $\begin{array}{l}\text { Renal disease with } \\
\text { GFR < 30 ml/min }\end{array}$ & 2.7 & 3 \\
\hline $\begin{array}{l}\text { History of substance abuse } \\
\text { Systolic heart failure }\end{array}$ & 1.7 & 2 \\
\hline $\begin{array}{l}\text { No ACEl or ARB therapy after } \\
\text { discharge }\end{array}$ & 1.8 & 2 \\
\hline
\end{tabular}

GFR - glomerular filtration rate, ACEI - angiotensin-converting enzyme inhibitor, $A R B$ - angiotensin receptor blocker.

compensation with less pulmonary congestion [22]. The interdependent physiology of the cardiopulmonary system and a rapid cycle of progressive deterioration related to shared structural pathology likely explain why COPD has the strongest association with early CHF readmissions $[23,24]$. Human immunodeficiency viral (HIV) disease is a cause of CHF, and these patients are managed for two complicated chronic illnesses, with significant drug interactions regarding their respective medical therapies [25]. The poly-pharmacy, including anti-retroviral and CHF medications, likely results in drug adverse effects which reduce compliance and precipitate CHF exacerbations [26].
Table IV. Total risk score and its correlation with risk of early readmission

\begin{tabular}{|lcc|}
\hline Risk Score & Frequency & $\begin{array}{c}\text { Risk of early } \\
\text { readmission (\%) }\end{array}$ \\
\hline$<5$ & $161(23.5 \%)$ & 2.50 \\
\hline $5-9$ & $325(47.5 \%)$ & 17.80 \\
\hline $10-14$ & $135(19.7 \%)$ & 49.60 \\
\hline $15-20$ & $13(1.9 \%)$ & 53.80 \\
\hline
\end{tabular}

The increased morbidity and mortality associated with concomitant renal disease with a glomerular filtration rate (GFR) less than $30 \mathrm{ml} / \mathrm{min} / 1.73 \mathrm{~m}^{2}$ and $\mathrm{CHF}$ are well documented, including perennial activation of the renin-angiotensin-aldosterone system, accelerated volume retention, and decreased diuresis [27]. Echocardiographic indices may be used to assess left ventricular diastolic dysfunction in patients with chronic kidney disease [28]. Syndecan-4 may be a useful biomarker for predicting adverse left ventricular remodeling in patients with CHF due to dilated cardiomyopathy [29]. Atrial fibrillation invariably results in episodic rapid ventricular rates, which further compromise diastolic filling and cardiac output in the setting of $\mathrm{CHF}$, with resultant decompensation requiring intervention $[30,31]$. Higher levels of physical activity in older community-dwelling adults were associated with a lower incidence of incident CHF [32]. Management of CHF in older adults is extensively discussed elsewhere [33-36].

The association between African-American ethnicity and early CHF readmissions is more complicated and likely involves the interaction of genetic, 
clinical and social factors. Studies have suggested that African Americans experience more rapid progression of CHF due to genetic polymorphisms [37]. In addition, the social realities of disproportionate poverty and limited access to medical care and therapeutic interventions, which contribute to continuing healthcare disparities, must also be considered. The increased morbidity and mortality associated with systolic heart failure compared to diastolic heart failure are related to the frequent irreversibility of decreased left ventricular function in these patients [38]. The more progressive clinical cycle of structural heart disease and pathological neurohormonal compensatory mechanisms likely accelerate the rate of early decompensation [39-41].

The evidence supporting the use of ACEI or ARB therapy in patients with systolic CHF has been well established. Patients unable to take these medications would be expected to experience increased morbidity and mortality from this disease [42]. The clinical impact of a history of substance abuse (supported by patient history and blood and urine toxicology studies, primarily alcohol and cocaine) on the pathophysiology and therapeutic management of heart failure is multiple-faceted [43]. These behaviors contribute to medical and healthcare non-compliance, rapid volume expansion, poor nutrition, myocardial ischemia, and worsening structural heart disease, and are invariably associated with limited social support systems, particularly in low-income communities [44-49].

The precise mechanisms by which the above individual clinical factors result in an independently significant increased risk of early CHF readmission, and whether they apply to other patient populations, will require additional and prospective studies for further delineation. Elucidating the clinical predictors of early CHF readmission in diverse patient populations remains an important focus of continuing investigation.

There have been many studies conducted on the predictors of early readmission for patients with CHF. However, only a few have investigated a predominantly African-American and Latino underserved urban population. Ghali et al. [15] conducted a prospective study in a similar patient population. However, the study size was small (101 patients). The results of this research identified cardiac arrhythmias as a clinical factor and predictor of early CHF readmission, similar to our finding of an increased risk of early readmission among CHF patients with atrial fibrillation. The other predictors of early readmission identified by Ghali et al. included poor compliance with medications and diet, emotional and environmental issues, lack of guideline-based drug therapy, pulmonary infections and thyrotoxicosis [15]. Philbin and DiSalvo [50] investigated predictors of early readmission for $\mathrm{CHF}$ and the development of a risk score. However, because this study relied primarily on administrative data, psychosocial and behavioral variables were not investigated. In addition, although this research included a large study population $(42,731)$ involving over 236 different hospitals in New York State, African Americans only represented $18.2 \%$ of the study population, as compared to $82 \%$ in the current investigation.

Vinson et al. [51] conducted a study to investigate early readmission among 161 elderly patients with CHF and evaluated all-cause early readmissions. Decompensated $\mathrm{CHF}$ accounted for $57 \%$ of the early readmissions. The clinical factors and predictors associated with early readmission included prior history of $\mathrm{CHF}$, four or more admissions within the preceding 8 years, CHF precipitated by acute myocardial infarction, and uncontrolled hypertension [51]. Calvillo-King et al. [52] conducted a systematic review to assess the impact of social factors on risk of readmission or mortality after hospitalization for community-acquired pneumonia and CHF. The study revealed that low socioeconomic status, lack of social support, being unmarried, and risk behaviors such as smoking and cocaine were significantly associated with readmission for $\mathrm{CHF}$ [52].

These studies and the current investigation highlight the complicated, complex and diverse clinical and social factors that impact on the early readmission rates of $\mathrm{CHF}$ patients. Many multivariate risk scores have been developed to model patient outcomes in CHF patients [53]. The system of scoring proposed in this study is both simple and convenient. The patient population analyzed in this study consists predominantly of African Americans (82\% of patients) and Latinos (12.7\% of patients) treated at a single medical center. Other ethnicities comprised only $5.3 \%$ of the study population. This represents a limitation of the study. Furthermore, it has been difficult to precisely describe the genetic profile of African Americans and Latinos, as they constitute a diaspora of immigrants from Africa and Latin America with contributions to the gene pool from other ethnic communities [8]. Another major limitation of this study is the lack of validation of the early risk stratification scoring system in prospective studies. Implementing strategies to reduce early CHF readmission, with a primary goal of improving morbidity and mortality, will require both inter-disciplinary innovation and community-specific research and interventions. Another major limitation of this study was that data on anemia, post-discharge brain natriuretic peptide (BNP), and social economic factors were not collected in all patients. 
Allocating resources for interventions in $\mathrm{pa}$ tients at particularly high risk for early CHF readmission will be more effective in reducing $\mathrm{CHF}$ readmissions, improving patients' morbidity and mortality, and reducing health care costs while preserving hospital reimbursements. Further validation of our risk scoring system prospectively is the subject of ongoing research with a goal of developing early $\mathrm{CHF}$ readmission prevention strategies which improve the morbidity and mortality of this high-risk patient population. The longer length of hospital stay in patients with no early readmission also needs further investigation.

In conclusion, developing a community-specific risk stratification model and scoring system to identify CHF patients at increased risk for early CHF readmission is an important strategy which may allow hospitals to reduce their early readmission rates. Once identified, these patients can be targeted for more intensified, goal-directed, customized, multidisciplinary management programs initiated during their index admission and continued after discharge. Allocating resources for interventions which involve those patients at particularly high risk for early CHF readmission will be more effective in reducing CHF readmissions, improving patients' morbidity and mortality, and reducing healthcare costs while preserving hospital reimbursements.

The current study proposes a risk scoring system for identification of CHF patients from a predominantly African-American and Latino underserved urban population based on independently significant clinical factors associated with early $\mathrm{CHF}$ readmission. Further validation of our risk scoring system prospectively is the subject of ongoing research with a goal of developing early $\mathrm{CHF}$ readmission prevention strategies which improve the morbidity and mortality of this high-risk patient population.

\section{Conflict of interest}

The authors declare no conflict of interest.

\section{References}

1. O'Connell JB, Bristow MR. Economic impact of heart failure in the United States: time for a different approach. J Heart Lung Transplant 1994; 13: S107-12.

2. Go AS, Mozaffarian D, Roger VL, et al. Heart disease and stroke statistics--2013 update: a report from the American Heart Association. Circulation 2013; 127: e6-245.

3. Bahrami H, Kronmal R, Bluemke DA, et al. Differences in the incidence of congestive heart failure by ethnicity: the multi-ethnic study of atherosclerosis. Arch Intern Med 2008; 168: 2138-45.

4. Wolinsky FD, Smith DM, Stump TE, Overhage JM, Lubitz RM. The sequelae of hospitalization for congestive heart failure among older adults. J Am Geriatr Soc 1997; 45: 558-63.
5. Cowie MR, Mosterd A, Wood DA, et al. The epidemiology of heart failure. Eur Heart J 1997; 18: 208-25.

6. Yancy CW. Heart failure in African Americans: a cardiovascular engima. J Card Fail 2000; 6: 183-6.

7. Bourassa MG, Gurne O, Bangdiwala SI, et al. Natural history and patterns of current practice in heart failure. The Studies of Left Ventricular Dysfunction (SOLVD) Investigators. J Am Coll Cardiol 1993; 22: 14A-9A.

8. Yancy CW, Strong M. The natural history, epidemiology, and prognosis of heart failure in African Americans. Congest Heart Fail 2004; 10: 15-8; quiz 21-2.

9. Bagchi AD, Stewart K, McLaughlin C, Higgins P, Croghan T. Treatment and outcomes for congestive heart failure by race/ethnicity in TRICARE. Med Care 2011; 49: 489-95.

10. Rodriguez F, Joynt KE, Lopez L, Saldana F, Jha AK. Readmission rates for Hispanic Medicare beneficiaries with heart failure and acute myocardial infarction. Am Heart J 2011; 162: 254-61 e3.

11. Joynt KE, Orav EJ, Jha AK. Thirty-day readmission rates for Medicare beneficiaries by race and site of care. JAMA 2011; 305: 675-81.

12. Jencks SF, Williams MV, Coleman EA. Rehospitalizations among patients in the Medicare fee-for-service program. N Engl J Med 2009; 360: 1418-28.

13. Mehra MR. From crisis intervention to preventive intervention. A new approach to the management of heart failure. Tex Heart Inst J 1998; 25: 251-4.

14. Kocher RP, Adashi EY. Hospital readmissions and the Affordable Care Act: paying for coordinated quality care. JAMA 2011; 306: 1794-5.

15. Ghali JK, Kadakia S, Cooper R, Ferlinz J. Precipitating factors leading to decompensation of heart failure. Traits among urban blacks. Arch Intern Med 1988; 148: 2013-6.

16. Satpathy C, Mishra TK, Satpathy R, Satpathy HK, Barone E. Diagnosis and management of diastolic dysfunction and heart failure. Am Fam Physician 2006; 73: 841-6.

17. Grossman W. Defining diastolic dysfunction. Circulation 2000; 101: 2020-1.

18. Naqvi TZ. Diastolic function assessment incorporating new techniques in Doppler echocardiography. Rev Cardiovasc Med 2003; 4: 81-99.

19. Heart Failure Society; Lindenfeld J, Albert NM, Boehmer JP, et al. HFSA 2010 Comprehensive Heart Failure Practice Guideline. J Card Fail 2010; 16: e1-194.

20. Cohn JN, Tam SW, Anand IS, et al. Isosorbide dinitrate and hydralazine in a fixed-dose combination produces further regression of left ventricular remodeling in a well-treated black population with heart failure: results from A-HeFT. J Card Fail 2007; 13: 331-9.

21. de Miguel Diez J, Chancafe Morgan J, Jimenez Garcia R. The association between COPD and heart failure risk: a review. Int J Chron Obstruct Pulmon Dis 2013; 8: 305-12.

22. Padeletti M, Jelic S, LeJemtel TH. Coexistent chronic obstructive pulmonary disease and heart failure in the elderly. Int J Cardiol 2008; 125: 209-15.

23. Westert GP, Lagoe RJ, Keskimaki I, Leyland A, Murphy $M$. An international study of hospital readmissions and related utilization in Europe and the USA. Health Policy 2002; 61: 269-78.

24. Le Jemtel TH, Padeletti M, Jelic S. Diagnostic and therapeutic challenges in patients with coexistent chronic obstructive pulmonary disease and chronic heart failure. J Am Coll Cardiol 2007; 49: 171-80.

25. Arshad A, Bansal A, Patel RC. Cardiac complications of human immunodeficiency virus infection: diagnos- 
tic and therapeutic considerations. Heart Dis 2000; 2: 133-45.

26. Sani MU, Okeahialam BN, Aliyu SH, Enoch DA. Human immunodeficiency virus (HIV) related heart disease: a review. Wien Klin Wochenschr 2005; 117: 73-81.

27. Herzog CA, Asinger RW, Berger AK, et al. Cardiovascular disease in chronic kidney disease. A clinical update from Kidney Disease: Improving Global Outcomes (KDIGO). Kidney Int 2011; 80: 572-86.

28. Franczyk-Skora B, Gluba A, Olszewski R, et al. Heart function disturbances in chronic kidney disease-echocardiographic indices. Arch Med Sci 2014; 10: 1109-16.

29. Bielecka-Dabrowa A, von Haehling S, Aronow WS, et al. Heart failure biomarkers in patients with dilated cardiomyopathy. Int J Cardiol 2013; 168: 2404-10.

30. Larned JM, Raja Laskar S. Atrial fibrillation and heart failure. Congest Heart Fail 2009; 15: 24-30.

31. Koitabashi T, Inomata T, Niwano S, et al. Paroxysmal atrial fibrillation coincident with cardiac decompensation is a predictor of poor prognosis in chronic heart failure. Circ J 2005; 69: 823-30.

32. Patel K, Sui X, Zhang Y, et al. Prevention of heart failure in older adults may require higher levels of physical activity than needed for other cardiovascular events. Int J Cardiol 2013; 168: 1905-9.

33. Alagiakrishnan K, Banach M, Jones LG, et al. Medication management of chronic heart failure in older adults. Drugs Aging 2013; 30: 765-82.

34. Alagiakrishnan K, Banach M, Jones LG, et al. Update on diastolic heart failure or heart failure with preserved ejection fraction in the older adults. Ann Med 2013; 45: 37-50.

35. McNamara DM. Pharmacogenetics in heart failure: genomic markers of endothelial and neurohumoral func tion. Congest Heart Fail 2004; 10: 302-8.

36. Franciosa JA, Ferdinand KC, Yancy CW, Consensus Statement on Heart Failure in African Americans Writing G. Treatment of heart failure in African Americans: a consensus statement. Congest Heart Fail 2010; 16: 27-38.

37. Bibbins-Domingo K, Fernandez A. BiDil for heart failure in black patients: implications of the U.S. Food and Drug Administration approval. Ann Intern Med 2007; 146: 52-6.

38. Chatterjee K, Massie B. Systolic and diastolic heart failure: differences and similarities. J Card Fail 2007; 13: 569-76.

39. Sarraf M, Masoumi A, Schrier RW. Cardiorenal syndrome in acute decompensated heart failure. Clin J Am Soc Nephrol 2009; 4: 2013-26.

40. Masoudi FA, Rathore SS, Wang Y, et al. National patterns of use and effectiveness of angiotensin-converting enzyme inhibitors in older patients with heart failure and left ventricular systolic dysfunction. Circulation 2004 110: 724-31.

41. Echemann M, Zannad F, Briancon S, et al. Determinants of angiotensin-converting enzyme inhibitor prescription in severe heart failure with left ventricular systolic dysfunction: the EPICAL study. Am Heart J 2000; 139 624-31.

42. Effects of enalapril on mortality in severe congestive heart failure. Results of the Cooperative North Scandinavian Enalapril Survival Study (CONSENSUS). The CONSENSUS Trial Study Group. N Engl J Med 1987; 316 1429-35.

43. Frishman WH, Del Vecchio A, Sanal S, Ismail A. Cardiovascular manifestations of substance abuse: part 2 alcohol, amphetamines, heroin, cannabis, and caffeine. Heart Dis 2003; 5: 253-71.
44. Hawkins NM, Jhund PS, McMurray JJ, Capewell S. Heart failure and socioeconomic status: accumulating evidence of inequality. Eur J Heart Fail 2012; 14: 138-46.

45. Jones CA, Perera A, Chow M, Ho I, Nguyen J, Davachi S. Cardiovascular disease risk among the poor and homeless - what we know so far. Curr Cardiol Rev 2009; 5 : 69-77.

46. Foraker RE, Rose KM, Suchindran CM, Chang PP, McNeill AM, Rosamond WD. Socioeconomic status, Medicaid coverage, clinical comorbidity, and rehospitalization or death after an incident heart failure hospitalization: Atherosclerosis Risk in Communities Cohort (1987 to 2004). Circulation Heart Fail 2011; 4: 308-16.

47. Rathore SS, Masoudi FA, Wang Y, et al. Socioeconomic status, treatment, and outcomes among elderly patients hospitalized with heart failure: findings from the National Heart Failure Project. Am Heart J 2006; 152: 371-8.

48. Ingelsson E, Lind L, Arnlov J, Sundstrom J. Socioeconomic factors as predictors of incident heart failure. J Card Fail 2006; 12: 540-5.

49. Sui X, Gheorghiade M, Zannad F, Young JB, Ahmed A. A propensity matched study of the association of education and outcomes in chronic heart failure. Int J Cardiol 2008; 129: 93-9.

50. Philbin EF, DiSalvo TG. Prediction of hospital readmission for heart failure: development of a simple risk score based on administrative data. J Am Coll Cardiol 1999; 33: 1560-6.

51. Vinson JM, Rich MW, Sperry JC, Shah AS, MCNamara T. Early readmission of elderly patients with congestive heart failure. J Am Geriatr Soc 1990; 38: 1290-5.

52. Calvillo-King L, Arnold D, Eubank KJ, et al. Impact of social factors on risk of readmission or mortality in pneumonia and heart failure: systematic review. J Gen Intern Med 2013; 28: 269-82.

53. Ketchum ES, Levy WC. Multivariate risk scores and patient outcomes in advanced heart failure. Congest Heart Fail 2011; 17: 205-12. 